\title{
A Brief Note of Nitrocellulose Membrane Applied for Biomedical Immobilization and Diagnosis
}

\author{
Ruochen Sun ${ }^{1}$, Song Gao ${ }^{2}$, Zhichao Feng ${ }^{2}$, Pingan Liu ${ }^{1,3 *}$ and Hui Qi ${ }^{1}$ \\ ${ }^{1}$ College of Aerospace and Civil Engineering, Harbin Engineering University, Harbin City, Heilongjiang Province, China \\ ${ }^{2}$ Hua An Industry Group Co., Ltd, Qiqihar City, Heilongjiang Province, China \\ ${ }^{3}$ Key Laboratory of Dual Dielectric Power Technology, Hebei Hanguang Industry Co. Ltd., Handan City, Hebei Province, China
}

*Corresponding author: Pingan Liu, College of Aerospace and Civil Engineering, Harbin Engineering University, Harbin City, Heilongjiang Province, China and Key Laboratory of Dual Dielectric Power Technology, Hebei Hanguang Industry Co. Ltd, Handan City Hebei Province, China.

To Cite This Article: Ruochen Sun, Song Gao, Zhichao Feng, Pingan Liu, Hui Qi. A Brief Note of Nitrocellulose Membrane Applied for Biomedical Immobilization and Diagnosis. 2020 - 9(5). AJBSR.MS.ID.001432. DOI: 10.34297/AJBSR.2020.09.001432.

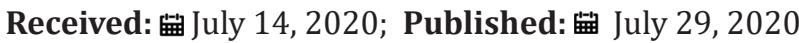

\section{Introduction}

Nitrocellulose (NC), obtained after nitration reaction, has a similar configuration with cellulose, so it is also named as cellulose nitrate [1]. As a fibre-like energetic material, NC is not limited in its original form and applications. One secondary product of $\mathrm{NC}$ is the NC membrane, which was described as the paper-like and microporous matrix [2]. The excellent signal-to-noise ratio [3], biocompatibility and stability of porous NC membrane substrates enable many relative biomedical applications, such as filtering [4,5], molecular immobilization and immuno-diagnosis. In this article, we are focused on these biomedical achievements of NC membrane.

Above all, the surface immobilization or modification allowed multifunctional applications of NC membrane. The approach for surface immobilization of NC membrane was various in previous studies. Firstly, some liquid substances could be directly adsorbed on NC membrane. For example, when NC membrane was adsorbed by $\left[{ }^{14} \mathrm{C}\right]$ tyrosinated tubulin, it could be used for the activity test of tubulin carboxypeptidase [6]. Then, Peng Zhang et al. [7] also prepared a circulating tumor cell capture substrate by this selfassemble phenomenon [7]. Secondly, the immobilization could be achieved with an "extra-assistance". The assistance could be acted from a binding media, such as gelatin. Because fibronectin has excellent gelatin binding performance, gelatin was successfully used as the media between NC membrane and fibronectin [8]. Despite the mentioned chemical media, external electric field could also promote the adsorption of NC membrane. As powered by electro kinetic phenomenon, a compact layer of protein was found to be adsorbed on the NC membrane [9].
As for the diagnosis applications, dot-ELISA is an important immunoassay method basing on NC membrane. As early as 1995, Kwabena M. Bosompem et al. [10] reported a destaining protocol for $\mathrm{NC}$ membrane by using hydrogen peroxide, which overcame the confusion caused by heavy staining on NC membrane [10]. In recent years, dot-ELISA has been proved to combine advantages of ELISA and EITB on the diagnosis of human trichinellosis [11]. Also, for serodiagnosis of avian reovirus and human strongyloidiasis, dotELISA was suggested as an effective alternative to ELISA $[12,13]$. Other animal, like cattle, could be diagnosed by DotELISA with low cost as well [14].

Besides, another diagnosis approach was about the combination of NC membrane with specified "detectors". South Korean scientists conjugated the magnetic beads with the antibody, then, this "bio-sensor" on NC membrane successfully detected the influenza A viruses [15]. Similarly, another research group from the same country detected the C-reactive protein by MCLW sensor, which was previously coated on NC membrane [16]. As the carrier to biosensors, NC membrane was concerned as well. American researchers even published a NC membrane immunoassay platform, which has different reagents to capture and control the detected biomolecules [17].

In nature, various bacteria and virus not only threaten human and animals but also plants. The ecosystem of the earth has its own balancing mechanism, but our demand of agricultural products is rising rapidly in the $21^{\text {st }}$ century. Therefore, the diagnosis of botanic virus is critical as well. As a cheap solid matrix, nitro 
pure NC membrane was applied for the detection of RNA from cucumoviruses and potyviruses [18].

No matter how the bio-diagnosis develops, efficiency and accuracy are always what we are seeking. On this occasion, the multiple diagnosis method will be necessary in the future. In order to further improve the efficiency of detection, the antibody array, which could detect multiple plant pathogens simultaneously, was developed on NC membrane substrate [19]. In 2018, another group reported the study on simultaneous detection of mycotoxins [20]. Next, the point-of-care detection technique will be another critical developing trend. It was believed that the hydrophobic coating on NC membrane would promote the binding of complexes, meanwhile, their sensitivity was higher than before [21]. To achieve the diagnostics with the point of care, Caitlin E. Anderson et al developed a novel 2-dimensional paper network which contained the NC membrane [22].

\section{Prospect}

It seems that investigations of $\mathrm{NC}$ membrane for biomedical application have been lasted for decades. It is also reasonable to believe that those studies will be continues, against the demand of global public health. The case of wastewater analysis by NC membrane in Eastern Cape South Africa [23] demonstrates that parts of current eco-protection techniques are still far from success. Since January 2020, human beings are now suffering Novel Coronavirus, 2019-nCoV. Will NC membrane contribute the detection of Novel Coronavirus? To my knowledge, it might be a considerable question. According to all references mentioned above, personally I think NC membrane might be useful in following aspects:

\section{A. The filtering of water source}

The microporous structure will help us confirm if 2019-nCoV has polluted the water source of the citizen.

B. The assemble of bio-sensor for 2019-nCoV.

In many countries, a large number of patients or potential patients are waiting to be diagnosed if they have been infected the 2019-nCoV. Therefore, more rapid diagnosis methods for COVID-2019 are urgently needed.

\section{Acknowledgment}

The authors research is supported by Fundamental Research Funds for Central Universities (3072020CFT0203).

\section{Reference}

1. Fernández de la Ossa MA, López López M, Torre M, García Ruiz C (2011) Analytical techniques in the study of highly-nitrated nitrocellulose. Trends in Analytical Chemistry 30(11): 1740-1755.

2. Sun S, Feng S, Ji C, Shi M, He X, et al. (2020) Microstructural effects on permeability of Nitrocellulose membranes for biomedical applications. Journal of Membrane Science 595: 117502.
3. Mujawar LH, Maan AA, Khan MKI, Norde W, van Amerongen A (2013) Distribution of biomolecules in porous nitrocellulose membrane pads using confocal laser scanning microscopy and high-speed cameras. Analytical Chemistry 85(7): 3723-3729.

4. Jones TH, Muehlhauser V, Thériault G (2014) Comparison of ZetaPlus 60S and nitrocellulose membrane filters for the simultaneous concentration of F-RNA coliphages, porcine teschovirus and porcine adenovirus from river water. Journal of Virological Methods 206: 5-11.

5. Fernández JG, Almeida CA, Fernández Baldo MA, Felici E, Raba J, et al. (2016) Development of nitrocellulose membrane filters impregnated with different biosynthesized silver nanoparticles applied to water purification. Talanta 146: 237-243.

6. Sironi JJ, Barra HS, Arce CA (2000) Tubulin carboxypeptidase assay based on the action of the enzyme on $\left[{ }^{14} \mathrm{C}\right]$ tyrosinated tubulin bound to nitrocellulose membrane. Analytical Biochemistry 279(1): 9-17.

7. Zhang P, Zhang R, Gao M, Zhang X (2014) Novel nitrocellulose membrane substrate for efficient analysis of circulating tumor cells coupled with surface-enhanced Raman scattering imaging. ACS Applied Materials \& Interfaces 6(1:) 370-376.

8. Chifflet S, Bolatto C, Tolosa S (2004) A rapid method for fibronectin purification on nitrocellulose membranes suitable for tissue culture. Journal of Biochemical and Biophysical Methods 59(2): 139-143.

9. Low SC, Shaimi R, Thandaithabany Y, Lim JK, Ahmad AL, et al. (2013) Electrophoretic interactions between nitrocellulose membranes and proteins: Biointerface analysis and protein adhesion properties. Colloids and Surfaces B Biointerfaces 110: 248-253.

10. Bosompem KM, Assoku RKG, Nantulya VM (1995) Hydrogen peroxide destaining: a new method for removing non-specific stains in nitrocellulose membrane-based dotELISA for the detection of trypanosomes in tsetse flies (Glossina spp.). Journal of Immunological Methods 187(1): 23-31.

11. Taher EE, Méabed EMH, El Akkad DMH, Kamel NO, Sabry MA (2017) Modified dot-ELISA for diagnosis of human trichinellosis. Experimental Parasitology 177: 40-46.

12. Majumder S, Chauhan TKS, Nandi S, Goswami PP, Tiwari AK, et al. (2018) Development of a recombinant $\sigma \mathrm{B}$ protein-based dot-ELISA for the diagnosis of avian reovirus (ARV). Journal of Virological Methods 257: 69-72.

13. Bosqui LR, Corral MA, Levy D, Bydlowski SP, Gryschek RCB, et al. (2020) Evaluation of the Dot-ELISA as a diagnostic test for human strongyloidiasis based on the detection of IgA in saliva. Acta Tropica 203: 105305.

14. Mohmad A, Chandra D, Saravanan BC, Manjunathchar HV, Kumar ORV, et al. (2018) Development of a recombinant TaSP-based DotELISA for detection of Theileria annulata infection in cattle. Ticks and Tick-borne Diseases 9(6): 1416-1420.

15. Hong HB, Krause HJ, Song KB, Choi CJ, Chung MA, et al. (2011) Detection of two different influenza A viruses using a nitrocellulose membrane and a magnetic biosensor. Journal of Immunological Methods 365(1-2): 95-100.

16. Kim BB, Im WJ, Byun JY, Kim HM, Kim MG, et al. (2014) Label-free CRP detection using optical biosensor with one-step immobilization of antibody on nitrocellulose membrane. Sensors and Actuators B: Chemical 190: 243-248.

17. Ramachandran S, Singhal M, McKenzie KG, Osborn JL, Arjyal A, et al. (2013) A rapid, multiplexed, high-throughput flow-through membrane immunoassay: A convenient alternative to ELISA. Diagnostics 3(2): 244260.

18. Chang PGS, McLaughlin WA, Tolin SA (2011) Tissue blot immunoassay and direct RT-PCR of cucumoviruses and potyviruses from the same NitroPure nitrocellulose membrane. Journal of Virological Methods 171(2): 345-351. 
19. Xiong L, Gao L, Liu Q, Xia J, Han X, et al. (2013) A simple, rapid and visual antibody array for the simultaneous detection of multiple plant pathogens. Analytical Methods 5: 2413-2418.

20. Zhang X, Wang Z, Fang Y, Sun R, Cao T, et al. (2018) Antibody microarray immunoassay for simultaneous quantification of multiple mycotoxins in corn samples. Toxins 10(10): 415.

21. Yew CHT, Azari P, Choi JR, Li F, Pingguan Murphy B (2018) Electrospincoating of nitrocellulose membrane enhances sensitivity in nucleic acidbased lateral flow assay. Analytica Chimica Acta 1009: 81-88.
22. Anderson CE, Buser JR, Fleming AM, Strauch EM, Ladd PD, et al. (2019) An integrated device for the rapid and sensitive detection of the influenza hemagglutinin. Lab on a Chip 19: 885-896.

23. Igwaran A, Iweriebor BC, Okoh AI (2018) Molecular characterization and antimicrobial resistance pattern of escherichia coli recovered from wastewater treatment plants in Eastern Cape South Africa. International Journal of Environmental Research and Public Health 15(6): 1237. 